\title{
Integrin $\beta_{3}$ Crosstalk with VEGFR Accommodating Tyrosine Phosphorylation as a Regulatory Switch
}

\author{
Xiaoxia Z. West ${ }^{19}$, Nahum Meller ${ }^{19}$, Nikolay L. Malinin ${ }^{1}$, Lalit Deshmukh ${ }^{2,3}$, Julia Meller ${ }^{1}$, Ganapati $\mathrm{H}$ \\ Mahabeleshwar ${ }^{1,4}$, Malory E. Weber ${ }^{1}$, Bethany A. Kerr ${ }^{1}$, Olga Vinogradova ${ }^{2 *}$, Tatiana V. Byzova ${ }^{1 *}$
}

1 Department of Molecular Cardiology, Lerner Research Institute, Cleveland Clinic, Cleveland, Ohio, United States of America, 2 Department of Pharmaceutical Sciences, School of Pharmacy, University of Connecticut, Storrs, Connecticut, United States of America, $\mathbf{3}$ Laboratory of Chemical Physics, National Institute of Diabetes and Digestive and Kidney Diseases, National Institutes of Health, Bethesda, Maryland, United States of America, 4 University Hospitals Harrington-McLaughlin Heart \& Vascular Institute and Case Cardiovascular Research Institute, Case Western Reserve University School of Medicine, Cleveland, Ohio, United States of America

\begin{abstract}
Integrins mediate cell adhesion, migration, and survival by connecting intracellular machinery with the surrounding extracellular matrix. Previous studies demonstrated the importance of the interaction between $\beta_{3}$ integrin and VEGF type 2 receptor (VEGFR2) in VEGF-induced angiogenesis. Here we present in vitro evidence of the direct association between the cytoplasmic tails (CTs) of $\beta_{3}$ and VEGFR2. Specifically, the membrane-proximal motif around ${ }^{801}$ YLSI in VEGFR2 mediates its binding to non-phosphorylated $\beta_{3} C T$, accommodating an $\alpha$-helical turn in integrin bound conformation. We also show that $Y^{747}$ phosphorylation of $\beta_{3}$ enhances the above interaction. To demonstrate the importance of $\beta_{3}$ phosphorylation in endothelial cell functions, we synthesized $\beta_{3} C T$-mimicking $Y^{747}$ phosphorylated and unphosphorylated membrane permeable peptides. We show that a peptide containing phospho- $Y^{747}$ but not $F^{747}$ significantly inhibits VEGF-induced signaling and angiogenesis. Moreover, phospho- $Y^{747}$ peptide exhibits inhibitory effect only in WT but not in $\beta_{3}$ integrin knock-out or $\beta_{3}$ integrin knock-in cells expressing $\beta_{3}$ with two tyrosines substituted for phenylalanines, demonstrating its specificity. Importantly, these peptides have no effect on fibroblast growth factor receptor signaling. Collectively these data provide novel mechanistic insights into phosphorylation dependent cross-talk between integrin and VEGFR2.
\end{abstract}

Citation: West XZ, Meller N, Malinin NL, Deshmukh L, Meller J, et al. (2012) Integrin $\beta_{3}$ Crosstalk with VEGFR Accommodating Tyrosine Phosphorylation as a Regulatory Switch. PLoS ONE 7(2): e31071. doi:10.1371/journal.pone.0031071

Editor: Christiana Ruhrberg, University College London, United Kingdom

Received July 27, 2011; Accepted January 1, 2012; Published February 17, 2012

Copyright: (c) 2012 West et al. This is an open-access article distributed under the terms of the Creative Commons Attribution License, which permits unrestricted use, distribution, and reproduction in any medium, provided the original author and source are credited.

Funding: This work was supported in parts by National Institute of Health (NIH) grants to TVB and American Heart Association and NIH grants to OV. The funders had no role in study design, data collection and analysis, decision to publish, or preparation of the manuscript. No additional external funding received for this study.

Competing Interests: A patent suggesting the utilization of integrin derived peptides for anti-angiogenesis treatment (Cleveland Clinic Foundation) is pending This does not alter the authors' adherence to all the PLOS ONE policies on sharing data and materials.

*E-mail: byzovat@ccf.org (TVB); olga.vinogradova@uconn.edu (OV)

9 These authors contributed equally to this work.

\section{Introduction}

Integrins are a family of transmembrane, heterodimeric glycoproteins composed of alpha and beta subunits. Each integrin subunit contains a large extracellular ligand-binding portion, a single membrane-spanning region, and a short cytoplasmic tail devoid of any enzymatic activity [1]. A crucial characteristic of all integrins, and particularly of the two members of the $\beta_{3}$ subfamily, $\alpha_{\mathrm{IIb}} \beta_{3}$ and $\alpha_{\mathrm{v}} \beta_{3}$, is their ability to become activated upon cell stimulation due to agonists or growth factors, a process termed 'inside-out' signaling. Activated integrins can bind to extracellular matrix components with high affinity and mediate, through 'outside-in' signaling events, many vital cellular processes such as adhesion, migration, and proliferation [2].

The $\beta$ subunits' CTs include two tyrosine phosphorylation sites, located within NPxY and/or NPxY-like motifs, and are known to interact with phosphotyrosine binding (PTB) domains of intracellular signaling mediators [3]. These interactions can regulate integrin activation states differentially. For example, talin serves as a major activator for non-phosphorylated $\beta_{3}$ [4,5], while Dok1 binds to $\beta_{3}$ phosphorylated at $Y^{747}$ with a higher affinity and thus, by replacing talin, favors the latent state of the receptor [6]. For $\alpha_{\text {IIb }} \beta_{3}$, the biochemical studies suggest that phosphorylation of both tyrosines $\left(\mathrm{Y}^{747}\right.$ and $\left.\mathrm{Y}^{759}\right)$ is required for the recruitment of myosin, while phosphorylation of $\mathrm{Y}^{759}$ alone is sufficient for interaction with the adapter protein Shc $[7,8]$. Our recent structural investigation established the underlying molecular mechanism behind the interaction between the Shc PTB domain and tyrosines phosphorylated $\left(\mathrm{Y}^{747}, \mathrm{Y}^{759}\right)$ on the $\beta_{3} \mathrm{CT}$ [9]. In addition, several studies have demonstrated that tyrosine phosphorylation of $\beta_{3}$ is involved in the regulation of $\alpha_{\mathrm{V}} \beta_{3}$ integrindependent adhesion, specifically under conditions of cell activation, and that $\mathrm{Y}^{747} \mathrm{~F}$ mutation diminished the stimulation-induced cell adhesion to vitronectin ( $\mathrm{VN}$ ), suggesting that phosphorylation is necessary for a fully functional $\alpha_{v} \beta_{3}[10,11,12,13]$. In addition, increases in the strength of the $\alpha_{\mathrm{v}} \beta_{3}$-VN interaction were shown to be dependent on phosphorylation of $\beta_{3}$ CT [11]. In contrast, $\alpha_{v} \beta_{3}$ mediated adhesion to fibronectin was shown to be abolished with increased $\beta_{3}$ phosphorylation [14]. Thus, several studies have demonstrated that tyrosine phosphorylation of $\beta_{3}$ integrin might support different aspects of integrin function. Consequences of integrin phosphorylation might be further modulated by interac- 
tions between integrin and intracellular mediators, the presence of which depends upon the cell type and the stage of cell adhesion and spreading.

We have previously demonstrated that $\alpha_{v} \beta_{3}$ function on the endothelium depends on its cross-talk with VEGF type receptor (VEGFR2) [15]. Endothelial cell (EG) stimulation by VEGF promotes a complex formation between $\alpha_{\mathrm{v}} \beta_{3}$ and VEGFR2, as well as a conformational change of $\alpha_{\mathrm{v}} \beta_{3}$ to a high affinity state [16]. VEGF treatment triggers phosphorylation of $\beta_{3} \mathrm{CT}$ on $\mathrm{Y}^{747}$ and $\mathrm{Y}^{759}$, which are located within the NPxY and NxxY motifs, respectively $[16,17]$. Mutations of these residues to phenylalanines inhibit the complex formation between VEGFR2 and $\beta_{3}$ integrin and VEGF-induced angiogenic responses $[16,17,18]$. The relationship between VEGFR2 and $\beta_{3}$ appears to be of a reciprocal nature, as $\beta_{3}$ phosphorylation also leads to enhanced phosphorylation and activation of VEGFR2 [16]. In the presence of normal $\beta_{3}$ expression, the interplay between the two receptors regulates a number of cellular responses underlying angiogenesis, including EC adhesion, migration, and formation of endothelial tube networks $[19,20]$. Based on our and others' findings that $\mathrm{Y}^{747} \mathrm{~F}$ $\mathrm{Y}^{759} \mathrm{~F}$ substitutions diminish adhesion to $\mathrm{VN}$ and integrin activity, we suggest that phosphorylation of these residues must play a pivotal role in regulation of integrin function $[10,11,12,13,16]$. In this study we have defined one of the VEGFR2 binding to $\beta_{3}$ motifs corresponding to its membrane-proximal region, we have shown that tyrosine-phosphorylation promotes the above interaction between $\beta_{3}$ and VEGFR2 CTs, and we have proved physiological significance of this interaction by confirming that $\beta_{3}$ derived $\mathrm{Y}^{747}$ containing inhibitory peptide diminishes EC tube formation and angiogenesis. Overall, these data provide novel molecular and mechanistic insights into phosphorylation dependent cross-talk between integrins and VEGF receptors.

\section{Results}

\section{VEGFR2 interacts with $\beta_{3} C T$ in a phosphorylation dependent manner}

Based on our findings that VEGFR2 regulates integrin activation and signaling [21] and that $\beta_{3}$ tyrosine phosphorylation is crucial for VEGF-induced tyrosine phosphorylation of VEGFR2 [22], we assessed whether the cytoplasmic portion of VEGFR2 binds directly to $\beta_{3} \mathrm{CT}$ and how tyrosine phosphorylation affects this interaction. Unlabeled synthetic peptide VpepA (sequence shown in Materials and Methods), representing the thirty membrane proximal residues of VEGFR2 cytoplasmic domain, was titrated into the solution of ${ }^{15} \mathrm{~N}$-labeled $\beta_{3} \mathrm{NP}$ (nonphosphorylated CT) and ${ }^{15} \mathrm{~N}$-labeled $\beta_{3} \mathrm{MP}$ (mono- $\mathrm{Y}^{747}$-phosphorylated CT). Associated chemical shift perturbations were monitored (Figure la and 1b). Chemical shift changes, plotted as a function of the residue number in $\beta_{3} \mathrm{CT}$, are shown in Figure 1c for $\beta_{3} \mathrm{NP}$ and Figure $1 \mathrm{~d}$ for $\beta_{3} \mathrm{MP}$. For non-phosphorylated $\beta_{3} \mathrm{CT}$, maximal perturbations occur near the membrane proximal region (residues ${ }^{716}$ KLLITIHDRK ${ }^{725}$ ), which might represent the primary binding site for VEGFR2. However, upon phosphorylation, in addition to the above region, maximal perturbations were recorded near the $\mathrm{Y}^{747}$ phosphorylation site $\left({ }^{744}\right.$ NPLYKEA $\left.^{750}\right)$. This finding represents the second binding site and, possibly, increased affinity. Although the chemical shift perturbations were rather modest, they were reproducible and concentration dependent, and reached saturation at a peptide to protein ratio of 3 to 1 , indicating the low affinity but specific nature of the observed interaction. Our attempts to calculate the dissociation constants from these titration series were unsuccessful due to low solubility and high tendency of the both VpepA and $\beta_{3} \mathrm{CT}$ to precipitate while forming the complex.

Thus, to further confirm and characterize the weak binding of VEGFR2-CTderived peptides to non-phosphorylated $\beta_{3}$, we have employed an additional trNOE-based approach. $\beta_{3} \mathrm{CT}$ was coupled to glutathione S-transferase $\left(\mathrm{GST}-\beta_{3}\right)$ and two smaller VEGFR2 peptides were synthesized (VpepB and VpepC; see Materials and Methods). TrNOE experiments, the method of choice for studying ultra-weak ligand-receptor pairs [23], were performed and the ratios of peptides to GST- $\beta_{3}$ were optimized for the most favorable NOE transfer (appeared to happen at a 50 to 1 ratio). The patterns of additional peaks observed for both VpepB and VpepC peptides when mixed with GST- $\beta_{3}$ were similar (Figure 1e and 1f, respectively), confirming the interaction between peptides and GST- $\beta_{3}$. However, since more trNOEs were detected for VpepB, this peptide was chosen for further structural analysis. The majority of the additional NOE peaks characterize residues of the region surrounding ${ }^{801} \mathrm{YLSI}^{804}$, indicating that this area assumes a bound conformation upon interaction with $\beta_{3} \mathrm{NP}$. It is imperative, however, for the ultra-weak interactions, such as described above, to confirm their specificity. For this reason, we performed negative control experiments. There were no additional peaks in NOESY spectra of GST-VpepB mixtures (data not shown) and thus we can confidently use this system for structural characterization of VEGFR2-derived peptides.

While the structural analysis was reported for extracellular ligand binding [24] and cytoplasmic kinase domains of VEGFR2 [25], no structural information is available regarding the membrane proximal region of VEGFR2. Accordingly, we performed structural calculations for VpepB bound to GST- $\beta_{3}$. VpepB exhibits a well defined C-terminal region $\left({ }^{801}\right.$ YLSIV $\left.^{805}\right)$, forming an $\alpha$-helical turn and an additional loop surrounding two Gly residues $\left({ }^{792} \mathrm{ANGGE}^{796}\right)$, whereas the remaining parts are unstructured. Figure $1 \mathrm{~g}$ shows a ribbon representation of VpepB along with ball and stick representation for residues ${ }^{801} \mathrm{YLSI}^{804}$. Figure $1 \mathrm{~h}$ illuminates backbone superposition of the 15 lowest energy conformers. Statistics for this ensemble are presented in Table 1 and the sequential connectivity map is shown in Figure S1. The NMR data has been deposited to BMRB (access code 18148).

Collectively, our data demonstrate that non-phosphorylated $\beta_{3} \mathrm{CT}$ interacts with VEGFR2, and this interaction involves the membrane proximal region within $\beta_{3} \mathrm{CT}$ and ${ }^{801} \mathrm{YLSI}^{804}$ motif within VEGFR2. $\beta_{3} \mathrm{Y}^{747}$ phosphorylation generates an additional VEGFR2 binding site within the ${ }^{744}$ NPLYKEA $^{750}$ region of $\beta_{3} \mathrm{CT}$, which is not susceptible to structural characterization using the approach employed for the non-phosphorylated $\beta_{3}$ (as we were unable to purify GST-fused mono- $\mathrm{Y}^{747}$-phosphorylated $\beta_{3} \mathrm{CT}$ ) and awaits the development of novel strategy for further investigation.

\section{$\beta_{3} \mathrm{CT}$ tyrosine phosphorylation and its consequences in endothelial cells}

Since our recent results $[26,27]$ indicate that phosphorylation of $\mathrm{Y}^{747}$ might stabilize the integrin activated state, and the data presented above show that $\mathrm{Y}^{74}$ phosphorylation also promotes $\beta_{3} \mathrm{CT}$ binding to VEGFR2, we next sought to assess the physiological consequences of $\beta_{3} \mathrm{CT}$ phosphorylation in ECs. To this end, we utilized a phosphopeptide containing a 16 amino acid sequence from $\beta_{3} \mathrm{CT}$ encompassing the ${ }^{744} \mathrm{NPLpY}^{747}$ motif [12] (pY747 peptide; Figure 2a). The peptide is expected to compete with endogenous binding partners for $\beta_{3} \mathrm{MP}$, including the VEGFR2 cytoplasmic domain. Previous studies have utilized the mutations of $\mathrm{Y}^{747}$ and $\mathrm{Y}^{759}$ to phenylalanines in order to simulate 
a
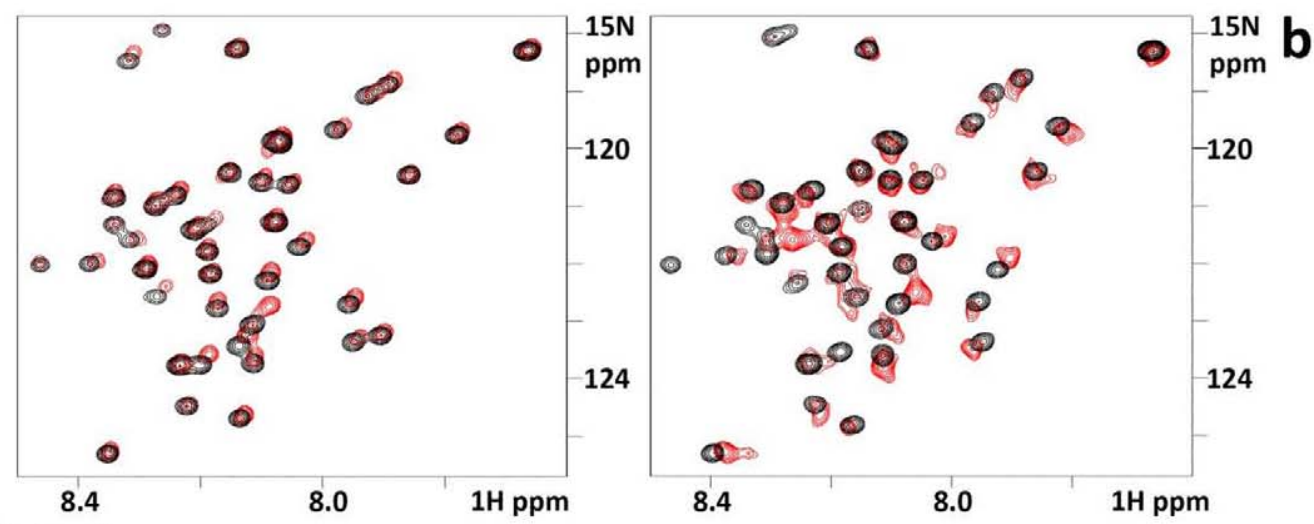

C Delta[ppm]

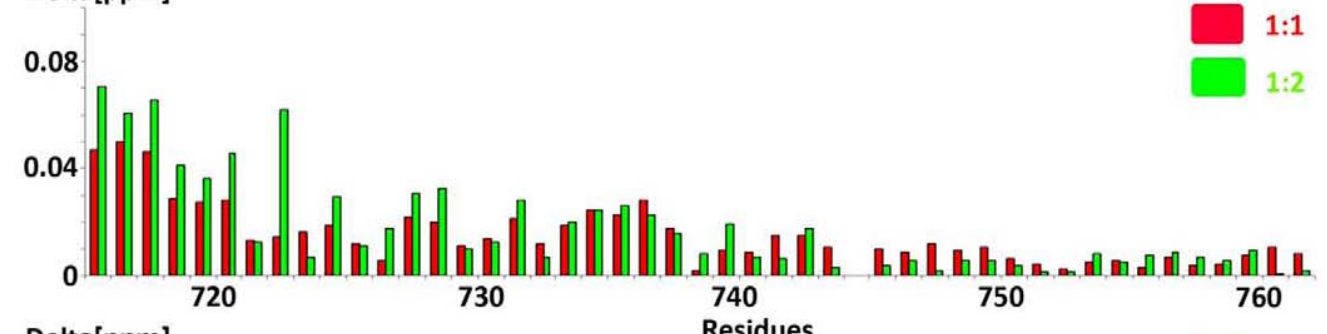

d Delta[ppm]

Residues

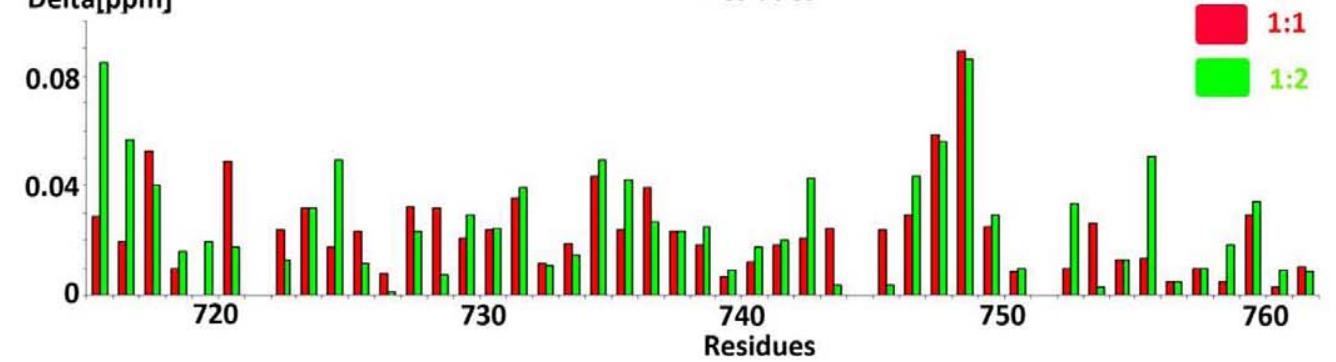

e

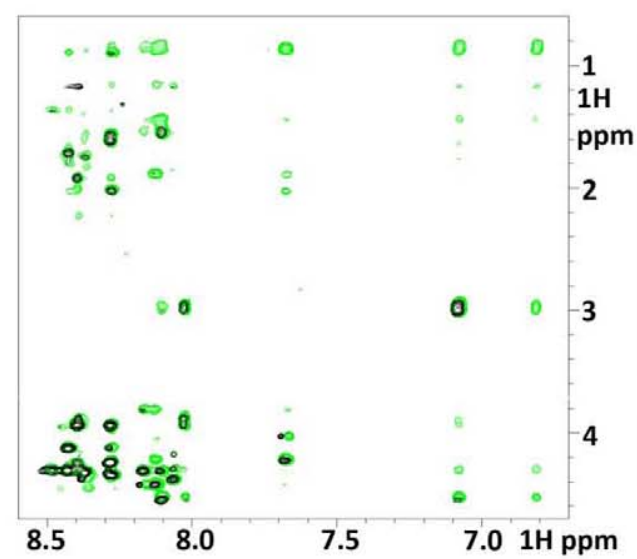

Residues
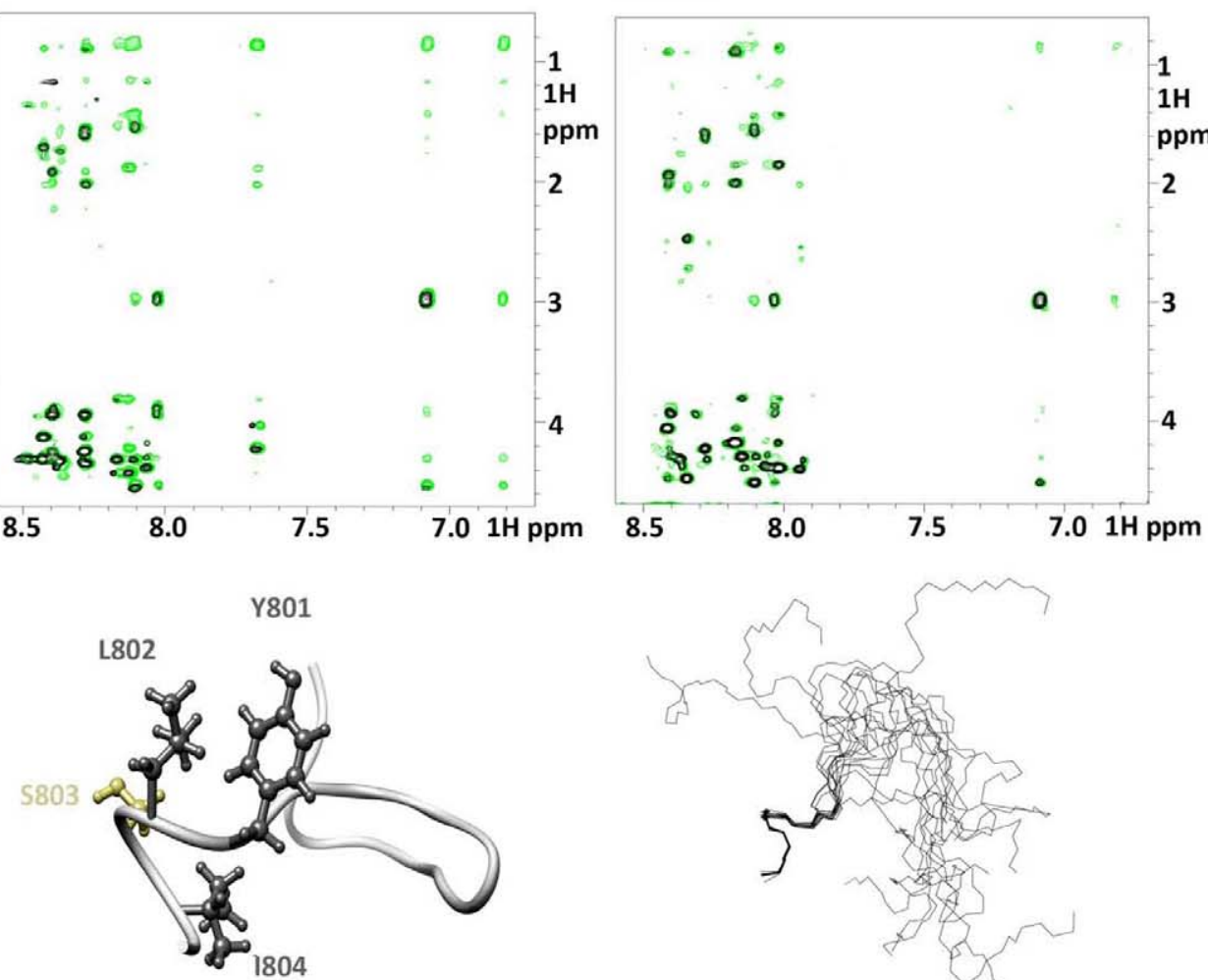

g

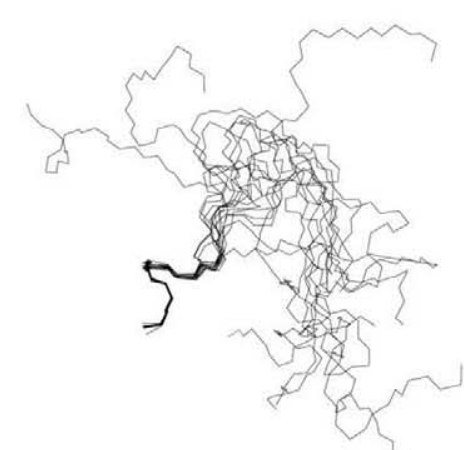

h 
Figure 1. Summary of the in vitro evidence for a direct interaction between VEGFR2 and $\beta_{3}$ CTs and structure of the VEGFR2 ${ }^{801}$ YLSI motif in bound conformation. Chemical shift titrations were performed in water at $25^{\circ} \mathrm{C}$ at $\mathrm{pH} 6.1$ with $\beta_{3}$ concentrations of in a range of $30-$ $100 \mu \mathrm{M}$. Expanded region of ${ }^{15} \mathrm{~N}$ HSQC spectra show chemical shift perturbations for a) $\beta_{3} \mathrm{NP}$. b) $\beta_{3} \mathrm{MP}$ in presence of VpepA at the ratio 1:1. c) Chemical shift changes in ${ }^{15} \mathrm{~N}$ labeled $\beta_{3} \mathrm{NP}$ upon addition of VpepA at the ratios of 1:1 (red) and 1:2 (green). d) Chemical shift changes in ${ }^{15} \mathrm{~N}$ labeled $\beta_{3} \mathrm{MP}$ upon addition of VpepA at the ratios of 1:1 (red) and 1:2 (green). Delta [ppm] refers to the combined $\mathrm{HN}$ and $\mathrm{N}$ chemical shift changes according to the equation: $\Delta \delta(\mathrm{HN}, \mathrm{N})=\left(\left(\Delta \delta_{\mathrm{HN}}{ }^{2}+0.2\left(\Delta \delta_{\mathrm{N}}\right)^{2}\right)^{1 / 2}\right.$, where $\Delta \delta=\delta_{\text {bound }}{ }^{-} \delta_{\text {free. }}$. Transferred NOEs: all the NOESY experiments were performed in $50 \mathrm{mM} \mathrm{NaCl}$ and $25 \mathrm{mM} \mathrm{Na}$-phosphate buffer at $\mathrm{pH} 6.1$ and $25^{\circ} \mathrm{C}$ with peptide to protein ratio of 50 to 1 and peptide concentrations of $1 \mathrm{mM}$; e) VpepB alone is shown in black and VpepB in combination with GST- $\beta_{3}$ is shown in green; f) VpepC alone (black) and VpepC in combination with GST- $\beta_{3}$ (green). g) Ribbon representation of VpepB structure. Hydrophobic residues of ${ }^{801}$ YLSI region are shown in dark gray. h) Backbone superimposition of the 15 lowest energy conformers of VpepB. Residues used for superimposition are ${ }^{801}$ YLSI. Molecular graphics images were produced using the UCSF Chimera package (Pettersen et al., 2004). doi:10.1371/journal.pone.0031071.g001

the non-phosphorylated state of $\beta_{3} \mathrm{CT}$. Therefore, in addition to a peptide containing nonphosphorylated ${ }^{744} \mathrm{NPLY}^{747}$ motif $(\mathrm{Y} 747$ peptide, we used a peptide bearing $\mathrm{Y}^{747} \mathrm{~F}$ mutation (F747 peptide) as controls in our studies (Figure 2a). The peptides were conjugated to an HIV-TAT leader sequence to allow delivery into cells. Indeed, the results of confocal microscopy analysis of ECs confirmed the uptake and the presence of the peptides within the cells and, most importantly, on the cell surface (Figure S2).

To assess the requirement of $\mathrm{Y}^{747}$ phosphorylation of $\beta_{3}$ for integrin-dependent angiogenic responses of ECs, three experimental systems were utilized. During angiogenesis, EGs reorganize to form a three-dimensional vessel structure [28], and this could be modeled in vitro in tube formation assays. Accordingly, tube formation by HUVEG treated with VEGF

Table 1. Structural statistics for the 15 final NMR structures of VpepB.

\begin{tabular}{ll}
\hline NMR distance constraints & \\
Distance constraints & 151 \\
\hline Total NOE & 48 \\
\hline Intra-residue & 103 \\
\hline Inter-residue & 72 \\
\hline Sequential $(|i-j|=1)$ & 31 \\
\hline Medium-range $(\mid i-j<5)$ & 0 \\
\hline Long-range $(|i-j|>=5)$ & 0 \\
\hline Hydrogen bonds & \\
Structure statistics & \\
Violations (mean and s.d.) & $0.045+/-0.007$ \\
\hline Distance constraints $(\AA)$ & 0.366 \\
\hline Max. distance constraint violation $(\AA)$ & \\
\hline Deviations from idealized geometry & $0.012+/-0.0001$ \\
\hline Bond lengths $(\AA)$ & $0.75+/-0.039$ \\
\hline Bond angles $\left({ }^{\circ}\right)$ & $0.36+/-0.027$ \\
\hline Impropers $\left({ }^{\circ}\right)$ & ordered residues $801-804$ \\
\hline Average pairwise r.m.s. deviation $(\AA)^{a}$ & 0.5 \\
\hline Heavy & 0.1 \\
\hline Backbone & \\
\hline Ramachandran plot & \\
\hline Most favored & $51.1 \%$ \\
\hline Additionally allowed & $44.4 \%$ \\
\hline Generously allowed & $4.4 \%$ \\
\hline Disallowed regions & $0.0 \%$ \\
\hline
\end{tabular}

a) Ordered residues (residues with sum of phi and psi order parameters $<1.8$ ) are considered for r.m.s.d. calculations and Ramachandran statistics.

doi:10.1371/journal.pone.0031071.t001 was assessed in the presence of $\beta_{3} \mathrm{CT}$-derived pY747, Y747, or F747 peptides. As shown in Figure 2b, VEGF-treated HUVEC formed a robust endothelial network. The tyrosine-phosphorylated peptide (pY747) inhibited this process, resulting in a disruption of the network's structure (Figure 2c). The thickness (Figure 2d), as well as the tube length (Figure 2f), of endothelial branches formed in the presence of pY747 peptide was significantly decreased compared to untreated cells. In contrast, cells treated with control F747 peptide were able to form a network of endothelial cords as robust as seen in untreated cells (Figure 2c). Unphosphorylated Y747 peptide exhibited only a weak or negligible effect (Figure 2c). In a similar assay, a peptide containing $\mathrm{pY}^{759}$ sequence from the second NPxY-like motif of $\beta_{3}$ had no inhibitory effect, emphasizing the unique role of $\mathrm{pY}^{747}$ residue (Figure 2e). In the aortic ring assay, pY747 was even more potent. The treatment with pY747, but not F747 or Y747 peptide, inhibited the sprouting of ECs stimulated by VEGF by more than $60 \%$ (Figure 3a and 3b). Next, the effect of pY747 peptide on in vivo angiogenesis induced by VEGF was evaluated. Matrigel containing (or lacking) VEGF and peptides was injected subcutaneously in C57BL/6 (wild type) mice. Seven days later, matrigel implants were removed, sectioned, and blood vessels were stained using CD31 antibody. The pY747 peptide inhibited VEGF-induced vascularization by more three-fold, while the control F747 or Y747 peptides had no effect (Figure 3c and 3d).

The pY747 peptide is predicted to mimic and compete with the phosphorylated form of endogenous $\beta_{3}$ integrin and, therefore, to also inhibit $\beta_{3}$ phosphorylation-dependent responses. Thus, this peptide should not have any inhibitory activity in mice characterized by the lack of $\beta_{3}$ phosphorylation $\left(\beta_{3}\right.$ knock-out mice or DiYF knock-in mice [29]), which, in turn, diminishes the complex formation between $\beta_{3}$ and VEGFR2 $[16,30]$. Indeed, as shown in Figure $4 \mathrm{a}$ and $4 \mathrm{~b}, \mathrm{pY} 747$ phosphopeptide could not effectively inhibit angiogenesis induced by VEGF in the aortic ring from $\beta 3^{-1-}$ mice, which is corroborated by the experiments with DiYF knock-in mice (Figure 4c). In addition, pY7474 peptide inhibition was specific to VEGF as no inhibition of basic fibroblast growth factor (bFGF) angiogenesis occurred in wild type, $\beta 3^{-/-}$, or DiYF mice (Figure 4c). Furthermore, the results from matrigel plug assay demonstrated that pY747 peptide resulted in inhibition of VEGF-induced angiogenesis in wild type, but not in DiYF mice, demonstrating the specificity of the approach (Figure 4d and 4e). Together, these results indicate that $\beta_{3}$ CT phosphorylation at $\mathrm{Y}^{747}$ positively regulates integrin-dependent responses in angiogenesis.

\section{VEGF-induced VEGFR2 phosphorylation and downstream signaling are diminished by pY747 peptide}

Studies from our lab and others demonstrated cross-activation of VEGFR2 and $\alpha_{v} \beta_{3}$ [16]. To test whether VEGFR2 activation and subsequent signaling were affected by pY747 peptide, we assessed $\mathrm{Y}^{1175}$ phosphorylation of VEGFR2, a major VEGFdependent VEGFR2 autophosphorylation site implicated in EG 
a

VpepA
Integrin $\beta_{3} C T$

pY747 peptide

Y747 peptide

F747 peptide

b

- VEGF

+ VEGF
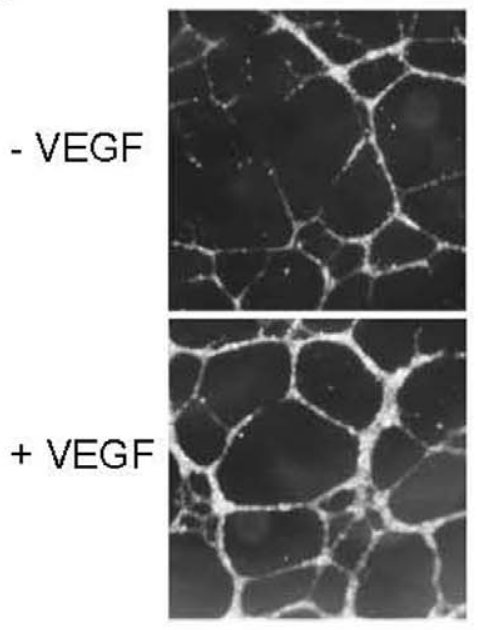

d

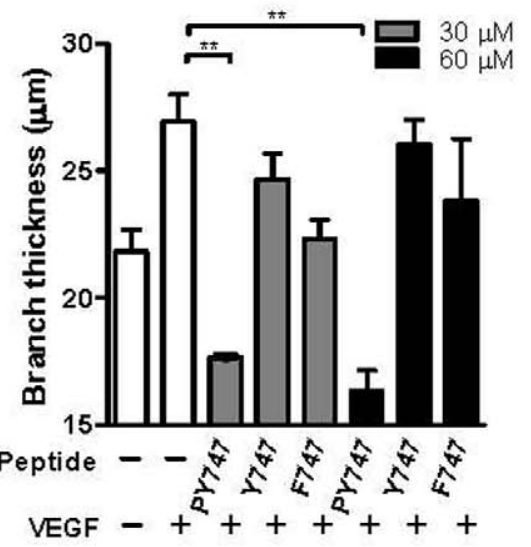

f

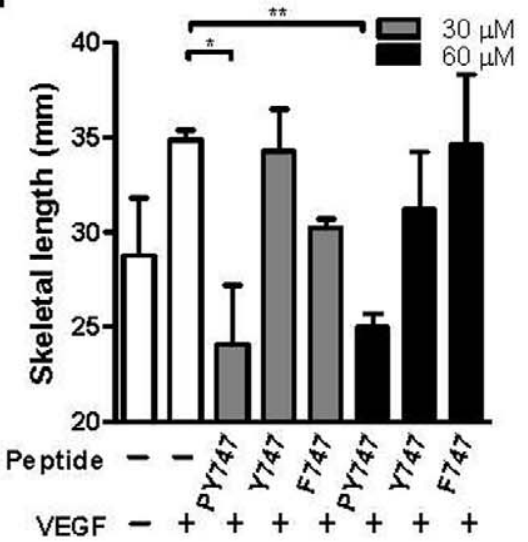

LRTVKRANGGELKTGYLSIVMDPDELPLDE

KLLITIHDRKEFAKFEEER ARAKWDTAN NPLY KEATSTF TNITYRGT

YGRKKRRQRRR DTAN NPLPY KEATSTFT - $\mathrm{COOH}$

YGRKKRRQRRR DTAN NPLY KEATSTFT - $\mathrm{COOH}$

YGRKKRRQRRR DTAN NPLF KEATSTFT- $\mathrm{COOH}$

C

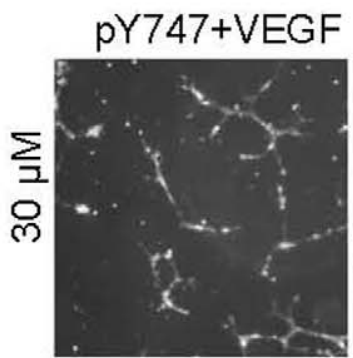

Y747+VEGF

F747+VEGF
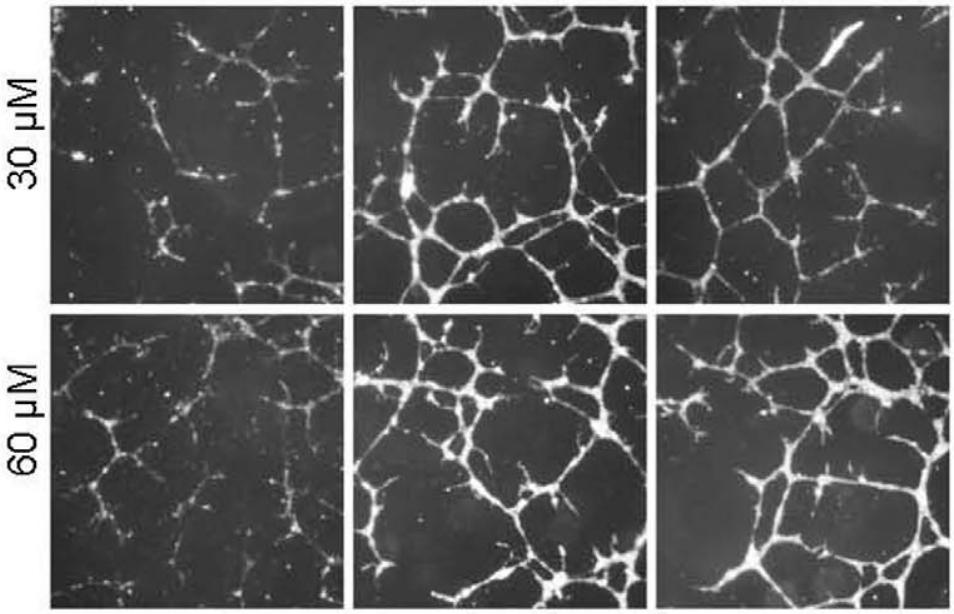

e

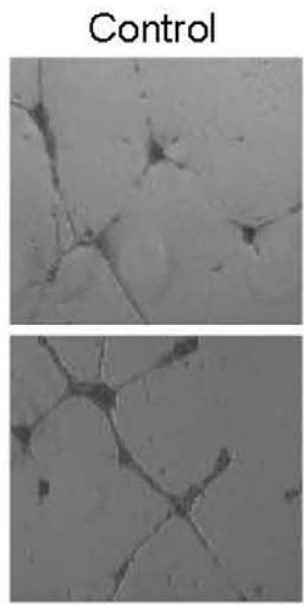

VEGF+pY747 VEGF+pY759
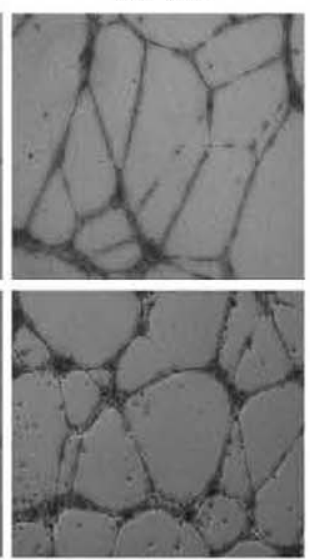
Figure 2. The pY747 peptide inhibits VEGFR2-induced angiogenesis in vitro. a) The amino acid sequences of VpepA, human integrin $\beta_{3}$ cytoplasmic tail (CT), and derived peptides. The conserved YLSI (VpepA), HDRKE (Integrin $\beta_{3} C T$ ) along with the two tyrosine phosphorylation motifs are shown in orange. HIV-TAT leader sequence (shown in blue) was added to allow delivery of the peptides across the cell membrane. b) Representative images of HUVEC tube formation in the presence with or without VEGF $(20 \mathrm{ng} / \mathrm{mL})$. c) Example images of inhibition of in vitro endothelial tube formation by the pY747 peptide. HUVEC were plated on matrigel-coated 48 well plates in the presence of $20 \mathrm{ng} / \mathrm{mL}$ VEGF and peptides at indicated concentrations. The cells were allowed to form tubes for 16 hours, bright field images at $2.5 \times$ magnification were taken and analyzed (using computer algorithms) for number, length, and thickness of branches. d) Quantitative result of branch thickness under different treatments. e) Representative images of tube formation in the presence of pY747 and pY759 peptide. f) Quantitative result of tube length as indicated.

doi:10.1371/journal.pone.0031071.g002

migration, along with ERK phosphorylation and subsequent DNA synthesis $[31,32]$. To this end, the phosphorylation status of $\mathrm{Y}^{1175}$ of VEGFR2 and ERK1/2 was assessed in ECs, which were treated with peptides with or without VEGF stimulation. Western blot analysis shows that treatment of cells with pY747 peptide resulted in inhibition of VEGFR2 and ERK1/2 phosphorylation in a dose-dependent manner with the maximal effect occurring at $40 \mu \mathrm{M}$ or higher concentrations; the control F747 peptide, however, had no effect (Figure 5). Thus, interference with intracellular signaling mediated by phosphorylated $\beta_{3}$ CT results in impaired activation of VEGFR2 and proangiogenic signaling events downstream of VEGFR2.

In contrast to VEGF, pY747 peptide had no effect on bFGFinduced activation of downstream signaling molecules, represented by phospho-ERK. As shown in Figure S3, ERK activation by bFGF was not affected in the presence of either pY747 or control F747 peptide. In these experiments, effects of VEGF were neutralized by VEGFR inhibitor, AAL-993. Together with results of NMR experiments (Figure 1) and previously published observations $[16,18]$, these data further emphasize the specificity and importance of a cross-talk between VEGFR2 and $\beta_{3}$ integrin. Together, our findings provide a structural basis for the cross-talk between $\beta_{3} \mathrm{CT}$ and VEGFR2 and show that this cross-talk mediates important cellular processes, such as VEGFR2 activation, EC tube formation, and angiogenesis.

\section{Discussion}

Over the last decade, the importance of the interplay between integrins and growth factor receptors was demonstrated in a number of physiologically important processes, including angiogenesis. At the same time, tyrosine phosphorylation of $\beta_{3}$ integrin has been identified as a major regulatory event for the modulation of this integrin function and its cross-talk with VEGF receptor. In the presented work, we have focused on the intertwining of these two processes. Using a NMR approach, we have documented a direct interaction between VEGFR2 and $\beta_{3}$ CTs, which appeared to be dependent upon $\mathrm{Y}^{747}$ phosphorylation of $\beta_{3}$.

In platelets, $\mathrm{Y}^{747}$ phosphorylation of $\beta_{3}$ occurs as a consequence of ligand binding and receptor clustering [33]. In this case, tyrosine phosphorylation appears to be involved in outside-in signaling $[7,29]$. In ECs, however, $\mathrm{Y}^{747}$ phosphorylation of $\beta_{3}$ occurs in response to VEGF stimulation in the absence of ligand. Here, we have shown that the phosphopeptide containing $\mathrm{pY}^{747}$ acts as an antagonist of VEGF-induced and integrin-mediated responses. It inhibits cellular processes known to be dependent on $\beta_{3}$ integrin activation, such as VEGF-induced endothelial tube formation, sprouting, and angiogenesis in vivo. Importantly, the phosphopeptide containing $\mathrm{pY}^{747}$ is a highly specific inhibitor for processes dependent on $\beta_{3}$ and its phosphorylation, since this peptide has no effect in DiYF knock-in mice expressing mutant $\beta_{3}$ unable to undergo phosphorylation as well as in $\beta_{3}$ knock-out mice.
Previous studies using cell systems with "activatable" $\alpha_{V} \beta_{3}$, such as myeloid K562 cells, demonstrated that that substitution of $\mathrm{Y}^{747}$ by phenylalanine impaired agonist-induced adhesion to $\mathrm{VN}$ $[10,13]$. A subsequent study demonstrated that firm adhesion of K562 cells to VN proceeds through three steps, and it is the second step characterized by a four-fold increase in receptor-ligand binding strength that was shown to be dependent on phosphorylation of $\mathrm{Y}^{747}$. In ECs, DiYF mutations of both $\mathrm{Y}^{747}$ and $\mathrm{Y}^{759}$ to phenylalanines affected VEGF-induced activation of $\alpha_{V} \beta_{3}$ and endothelial responses [16]. However, in Chinese hamster ovary (CHO) cells, expressing $\alpha_{\mathrm{V}} \beta_{3}$, a cell model generally characterized by the lack of inside-out integrin signaling, the $\mathrm{Y}^{747} \mathrm{~F}$ mutation did not affect binding of fibrinogen-coated beads [33]. A possibility of indirect inhibitory effect of $\beta_{3}$ phosphorylation was reported in a study utilizing expression of temperature-sensitive $\mathrm{v}$-Src in osteosarcoma cells. In this study, increased $\beta_{3}$ phosphorylation correlated with reduced $\alpha_{V} \beta_{3}$-fibronectin binding strength, which was rescued by the $\mathrm{Y}^{747} \mathrm{~F}$ mutation [14]. However, many mutagenesis studies using a well-defined integrin activation monitoring system, i.e. binding of soluble monovalent ligand, demonstrate that mutations of $\mathrm{Y}^{747}$ to $\mathrm{F}$ generally diminish integrin function. This effect might also be attributed to the disruption of binding sites for key integrin activators, such as talin and kindlin. In this regard, our data showing differential effects of $\beta_{3}$ phosphopeptide containing $\mathrm{pY}^{747}$ versus its unphosphorylated form are crucial in demonstrating the role of phosphorylation of this integrin, per se. Of particular interest is the fact that the effect of phosphorylation may differ for other subfamilies of $\beta$ integrins. For example, in mice whose tyrosines of the $\beta_{1}$ tail were mutated to phenylalanines $\left(\mathrm{YY}^{783 / 795} \mathrm{FF}\right)$, no obvious defects have been observed [34]. Again, use of the $\mathrm{Y}$ to $\mathrm{F}$ mutations need to be interpreted with an understanding that these mutations might affect events other than the direct consequences of phosphorylation. These reservations concerning mutagenesis studies emphasize the importance of the structural analysis presented in this study, which allowed direct comparison of phosphorylated versus unphosphorylated form of $\beta_{3}$.

$\mathrm{Y}^{747}$ phosphorylation in $\beta_{3} \mathrm{CT}$ appears to promote a complex formation with VEGFR2, and this complex is not present in DiYF mutant cells [18]. Our data show not only the presence of the $\beta_{3^{-}}$ VEGFR2-CTs complex, but also the key regulatory role of the $\mathrm{Y}^{747}$ phosphorylation site in this complex formation. Furthermore, $\beta_{3}$ CT-derived $\mathrm{Y}^{747}$-phosphorylated peptide was able to disrupt VEGF-induced signaling, EC tube formation, and angiogenesis, in contrast to the unphosphorylated control. Thus, our in vitro data supports in vivo observations that $\beta_{3} \mathrm{CT}$ phosphorylation is crucial for the interaction and cross-talk with VEGFR2 [16,18]. This interaction performs a key regulatory function in pathological angiogenesis [18], and new structural insights into this mechanism may permit the design of novel anti-angiogenic compounds. While we demonstrate that phosphorylation of the $\mathrm{Y}^{747}$ likely increases the affinity of $\beta_{3}$ for VEGFR2-derived, membrane-proximal peptides, additional phosphorylation of $\mathrm{Y}^{759}$ might diminish this effect (data not shown). This finding may indicate a key role for the 
a
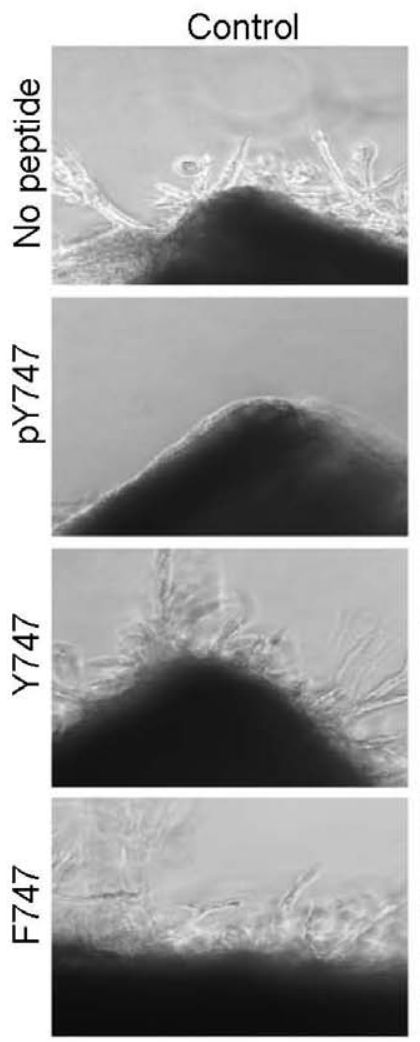

C
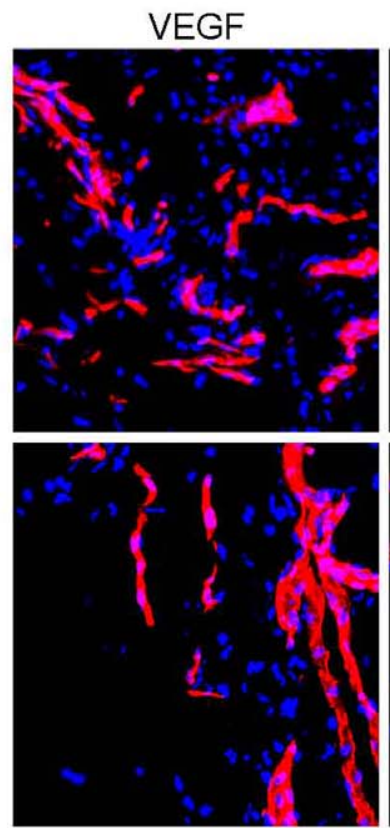

VEGF+Y747
VEGF
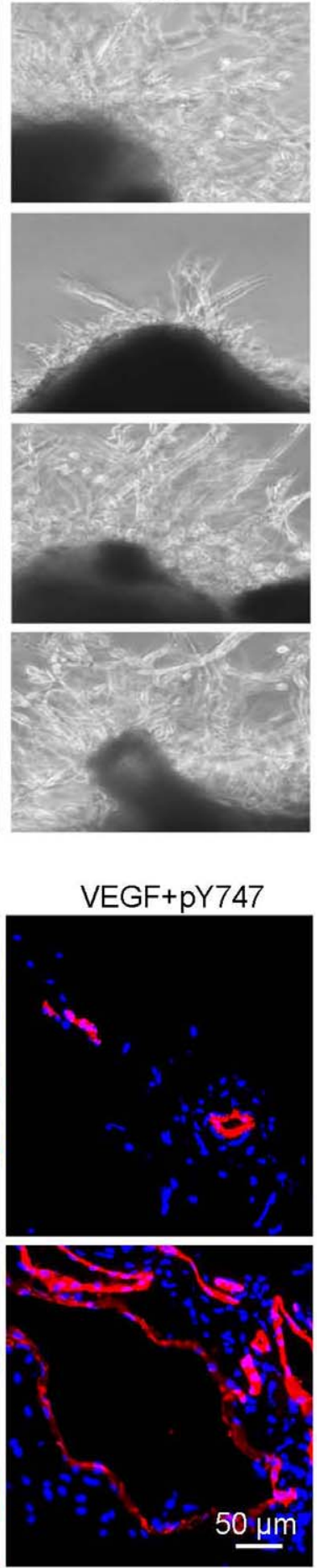

VEGF+F747 b

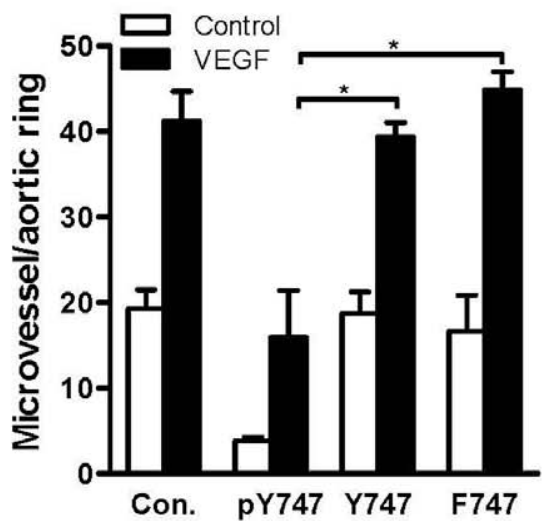

d

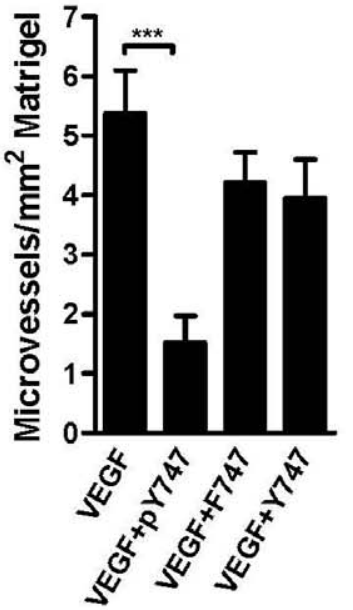

Figure 3. The pY747 peptide inhibits VEGFR2-induced angiogenesis in ex vivo and in vivo. a) Inhibition of ex vivo endothelial sprouting by the pY747 peptide. Mouse aortic rings were embedded in matrigel in the presence or absence of $40 \mathrm{ng} / \mathrm{mL}$ of VEGF and peptides as indicated. Photographs were taken at three days and the number of endothelial sprouts originating from each ring was determined. b) Quantification of aortic ring assay as indicated in Fig. 3a. c) Inhibition of in vivo angiogenesis by pY747 peptide. Results of matrigel plug angiogenesis assay are shown. The indicated peptides at $200 \mu \mathrm{M}$ concentration were mixed with growth factor-reduced matrigel containing VEGF $(500 \mathrm{ng} / \mathrm{mL})$ and injected subcutaneously into wild type mice. Seven days later, the matrigel implants were removed, sectioned, and blood vessels were stained with CD31 Ab (red) and nuclei with DAPI (blue). Vessel area was determined using ImagePro. d) Quantified results of matrigel plug assay as indicated in Fig. 3c. doi:10.1371/journal.pone.0031071.g003 
a

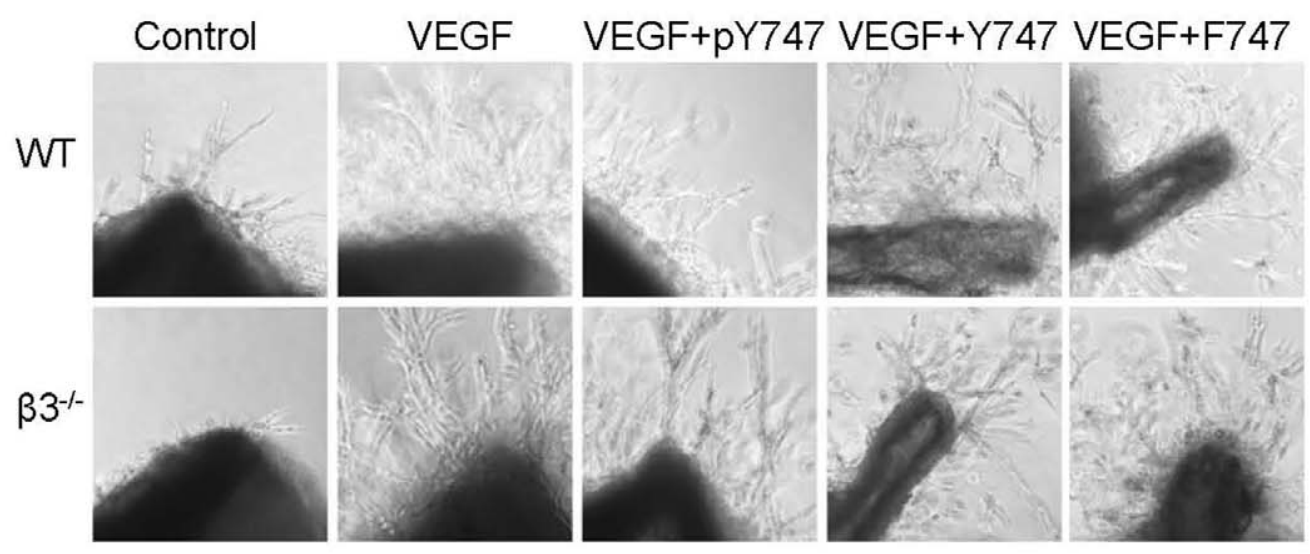

b
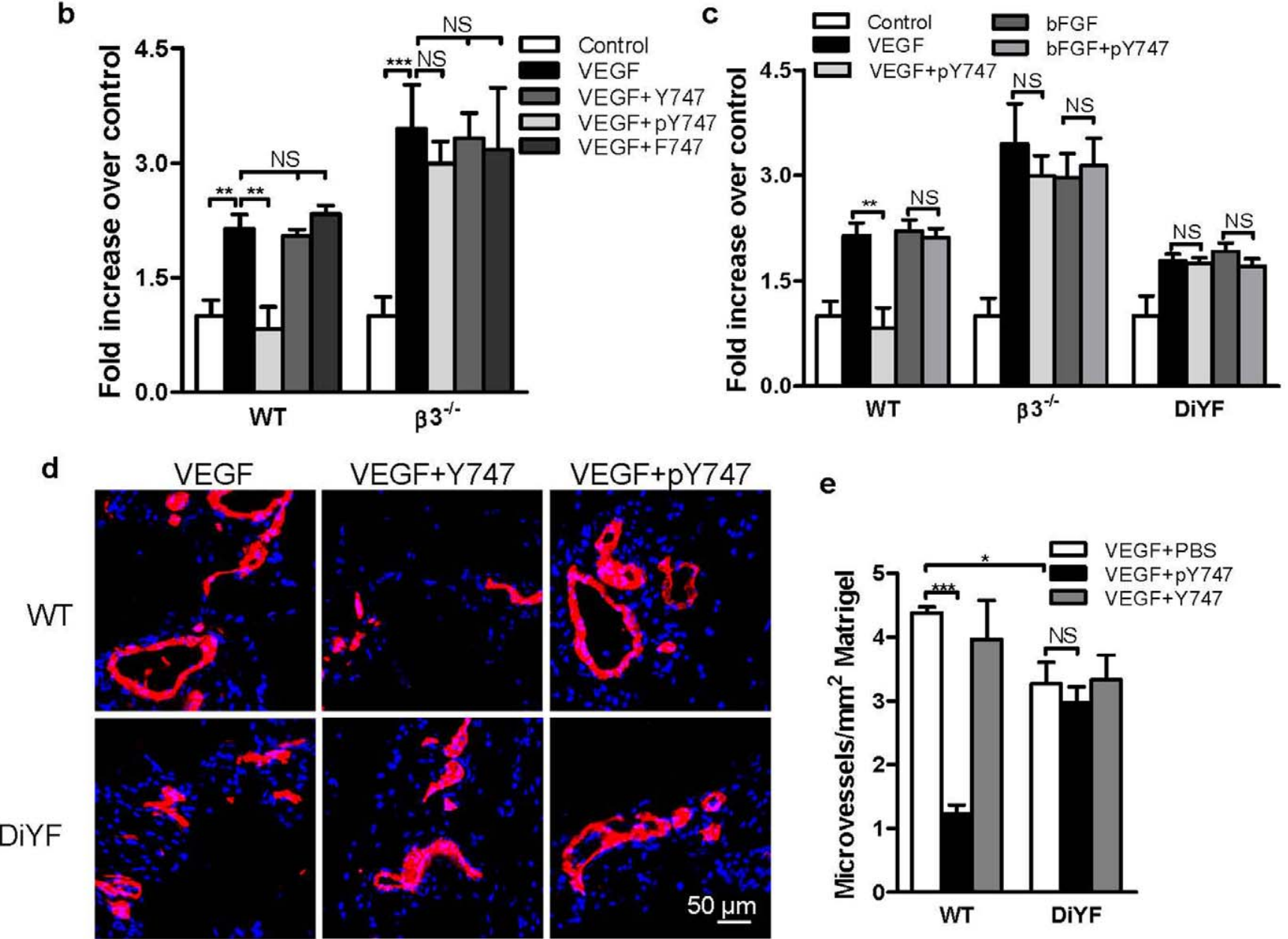

e
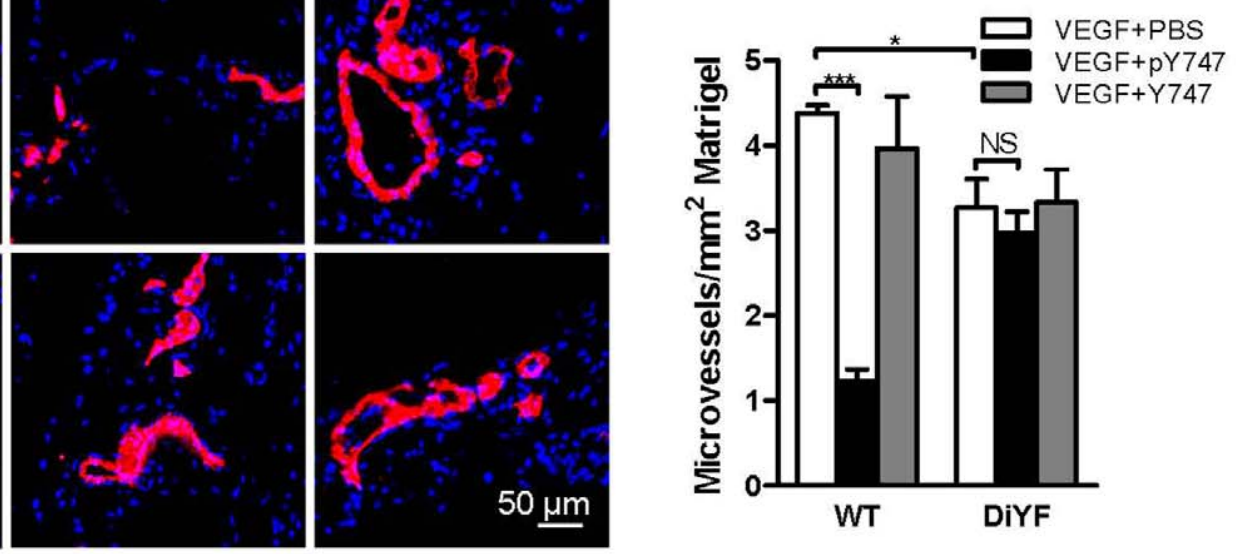

Figure 4. The pY747 peptide has no effect on $\boldsymbol{\beta 3}^{-1-}$ or DiYF mice. a) pY747 peptide does not inhibit VEGF-induced aortic ring growth from $\beta 3^{-1-}$ mice. Mouse aortic rings were embedded in matrigel in the presence of $40 \mathrm{ng} / \mathrm{mL}$ of VEGF and $40 \mu \mathrm{M}$ of peptides as indicated. b) Quantification of aortic ring assay as indicated in Fig. 4a. c) pY747 could not inhibit bFGF-induced aortic ring growth, Mouse aortic rings were isolated from wild type (WT), $\beta 3^{-1-}$, and DiYF mice and embedded in matrigel in the presence of $40 \mathrm{ng} / \mathrm{mL}$ of VEGF, $20 \mathrm{ng} / \mathrm{mL}$ of bFGF or pY747 peptides as indicated. Aortic rings were incubated for 3 days for wild type and $\beta 3^{-/-}$aortic rings and 4 days for DiYF aortic rings (longer incubation was used to obtain visible aortic sprouting which is diminished in these mice). d) pY747 peptide does not inhibit angiogenesis in DiYF mice. Peptides' effect on in vivo angiogenesis in wild type mice and DiYF mice was tested as described. e) Quantification of blood vessels in matrigel plus assay as indicated. 

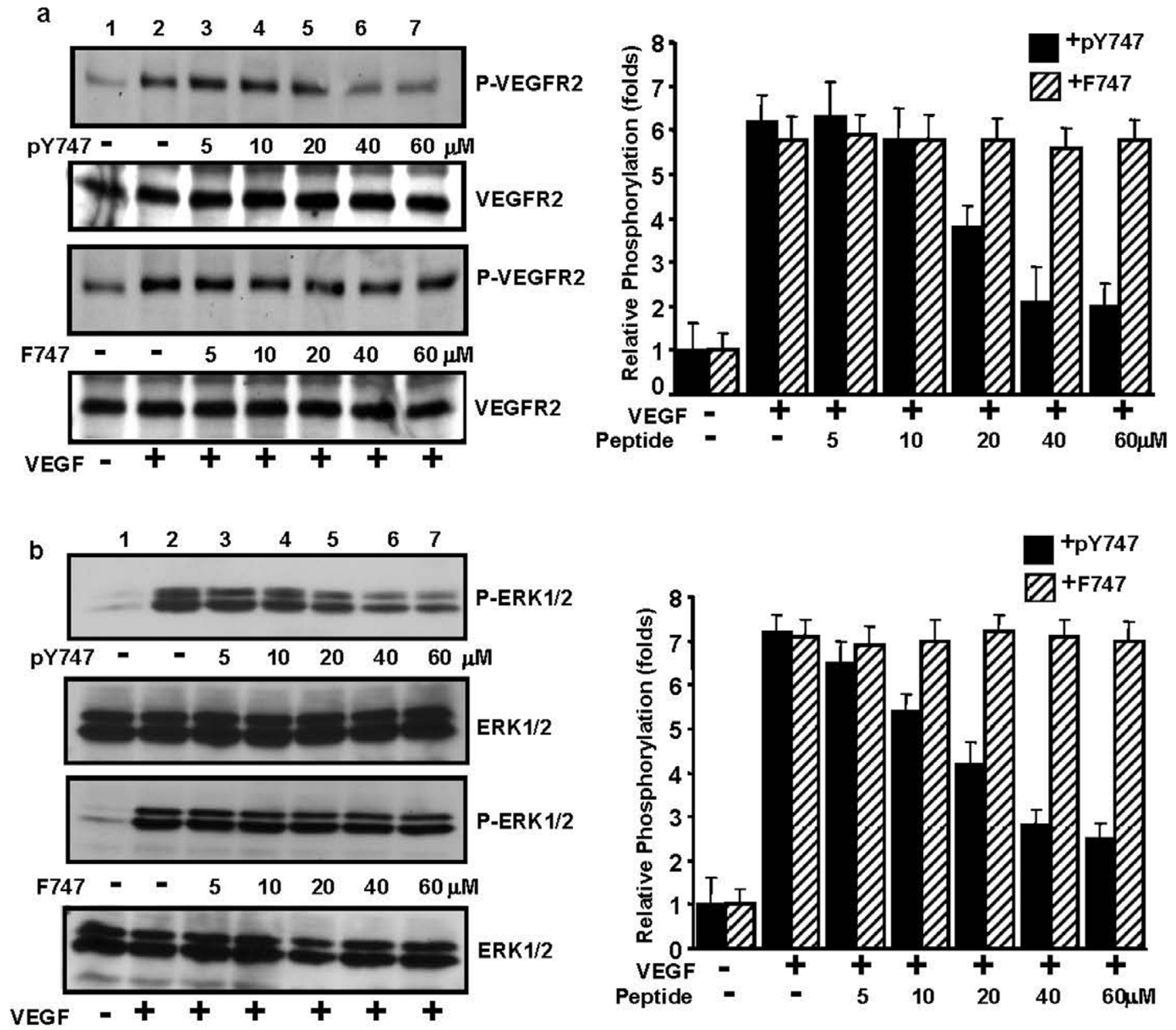

Figure 5. pY747 peptide inhibits VEGF-induced VEGFR2 phosphorylation and ERK activation. Serum starved HUVEC were incubated with the indicated concentrations of pY747 or F747 peptides for $3 \mathrm{~h}$, then stimulated with $20 \mathrm{ng} / \mathrm{mL}$ VEGF for five min at $37^{\circ} \mathrm{C}$ or left unstimulated. The cells were lysed and equal amounts of protein from total cell lysates were subjected to Western blot analysis with a) anti-p-VEGFR2 (Y1775) Ab or b) anti-p-ERK1/2 antibodies. The blots were reprobed with a) anti-total VEGFR2 or b) anti-total ERK1/2 antibodies as loading control. Bands were quantified by densitometric analysis and fold increase over unstimulated cells are displayed (right panels).

doi:10.1371/journal.pone.0031071.g005

$\mathrm{NPLY}^{747}$ motif in positive regulation of the cross-talk between VEGFR2 and $\beta_{3}$ [30], which is in agreement with differences in the kinetics of $\mathrm{Y}^{747}$ vs. $\mathrm{Y}^{759}$ phosphorylation in response to VEGF in ECs [18].

To conclude, we have shown direct complex formation between cytoplasmic tails of $\beta_{3}$ integrin and VEGFR2 in vitro, structurally characterized one of the VEGFR2 binding motifs, and confirmed that the above interaction is further enhanced by $\mathrm{Y}^{747}$ phosphorylation of $\beta_{3}$ integrin. We also showed in vivo that $\mathrm{pY}^{747}$ affects $\beta_{3}$ integrin cross-talk with VEGFR2 resulting in suppressed VEGFinduced signaling, endothelial tube formation, and angiogenesis. These findings identify important regulatory elements controlling the activity of $\beta_{3}$ integrins in ECs, which underlie a number of more complex responses, including thrombosis/haemostasis and pathological angiogenesis.

\section{Materials and Methods}

Peptide synthesis

Short peptides corresponding to the membrane proximal region of VEGFR2, VpepA $\left({ }^{786}\right.$ LRTVKRANGGELKTGYLSIVMDPDELPLDE $\left.^{815}\right)$, VpepB ( ${ }^{786}$ LRTVKRANGGELKTGYLSIV $\left.^{805}\right)$, VpepC $\left({ }^{791}\right.$ RANGGELKTGYLSIVMDPD $\left.{ }^{809}\right)$, and membranepermeable corresponding to $\beta_{3} \mathrm{CT}$ peptides, $\mathrm{pY}^{747}$ (YGRKKRRQRRRDTANNPLPYKEATSTFT), $\mathrm{Y}^{747}$ (YGRKKRRQRRRDTANNPLYKEATSTFT), and $\mathrm{F}^{747}$ (YGRKKRRQRRRDTANNPLFKEATSTFT) were synthesized in the Cleveland Clinic Molecular Biotechnology Core laboratory byFmoc chemistry using solid phase Omega 396 synthesizer (Advanced ChemTech, Louisville, KY). Quality analysis of the peptides was performed by HPLC on an analytical reverse phase C-18 column and by matrix 
assisted laser desorption ionization time-of-flight (MALDI-TOF) mass spectrometry (MS).

\section{Expression and Purification}

Cloning, expression, and purification of $\beta_{3} \mathrm{CT}$ and GST- $\beta_{3}$ have been described previously [5,35]. To produce ${ }^{15} \mathrm{~N}$ isotopically labeled $\beta_{3} \mathrm{CT}$ cells were grown in M9 minimal medium containing ${ }^{15} \mathrm{NH}_{4} \mathrm{Cl}(1.1 \mathrm{~g} / \mathrm{L})$. Tyrosine phosphorylation of $\beta_{3} \mathrm{CT}$ has been achieved in vivo by using TKB1 bacterial cell line from Stratagene following the manufacture's protocol for the recombinant protein induction as described elsewhere [26].

\section{NMR Spectroscopy}

${ }^{1} \mathrm{H}^{15} \mathrm{~N}$ Heteronuclear single quantum correlation (HSQG) titration experiments were performed in water at $25^{\circ} \mathrm{C}$ on Varian Inova $600 \mathrm{MHz}$ equipped with inverse-triple resonance cryoprobe. Chemical shifts assignments have been determined previously [5] and have been modified to address the effect of phosphorylation. Transferred NOESY experiments for different peptides were performed at $\mathrm{pH}$ 6.1. Different ratios of the peptides to the binding partner were investigated to find the optimal range for NOE transfer for each particular analysis. All the spectra were processed with NMRPipe [36] and analyzed by CCPN software suite [37]. The resonance assignments of unlabeled peptides were made using conventional 2D ${ }^{1} \mathrm{H}-{ }^{1} \mathrm{H}$ TOCSY and NOESY spectra [38] by CCPN software suite [37].

\section{Structure Calculation}

Sequence-specific assignments of integrin tails are described elsewhere [5]. Restraints from two dimensional ${ }^{1} \mathrm{H}-{ }^{1} \mathrm{H}$ NOESY experiment were used for the structure calculations. The structures were calculated based on the hybrid distance geometry-dynamical simulated annealing method using the X-PLOR-NIH [39]. The target function minimized during simulated annealing (as well as during conventional Powell minimization) comprises only quadratic harmonic terms for covalent geometry, square-well quadratic potentials for the experimental distance restraints. Best structures from the ensembles have been chosen based upon lowest Lennard-Jones potential. None of the structures have NOE violations greater than $0.5 \AA$. The Protein Structure Software suite (PSVS; courtesy of CABM Structural Bioinformatics Laboratory, Rutgers State University of New Jersey) was used for structure validation (http://psvs-1_3.nesg.org/).

\section{Materials and Animals}

Rabbit polyclonal anti-VEGFR2, anti- $\beta_{3}$-integrin, and mouse monoclonal anti-phospho tyrosine antibodies were purchased from Santa Cruz Biotechnology, Inc. (Santa Cruz, CA). AntiERK1/2, Anti-p-ERK1/2, and anti-phospho-VEGFR2 were from Cell Signaling Technology (Beverly, MA). VEGF was purchased from R\&D Systems (Minneapolis, MN) and matrigel was obtained from BD Biosciences (San Jose, CA). DiI was obtained from Invitrogen (Carlsbad, CA). Drabkin's reagent was from Sigma. C57BL/6 (wild type), $\beta_{3}$ knock-out (C57BL/6 background), and DiYF knock-in (in DiYF mice, the $\beta_{3}$ integrin tyrosines 747 and 759 are mutated to phenylalanine, C57BL/6 background [29]) mice were housed and treated according to Cleveland Clinic Institutional Animal Care and Use Committee regulations.

\section{Cell culture}

Human umbilical cord vein endothelial cells (HUVEG) were grown in DMEM:F12 media supplemented with 15\% FBS,
$100 \mathrm{U} / \mathrm{mL}$ penicillin, $100 \mu \mathrm{g} / \mathrm{mL}$ streptomycin, $90 \mu \mathrm{g} / \mathrm{mL}$ heparin sulfate, and $90 \mu \mathrm{g} / \mathrm{mL}$ endothelial cell growth factor. Lung ECs: Mouse lungs were excised, minced, and digested using a collagenase-dispase reagent (Roche Diagnostics, Indianapolis, IN). Digests were strained and the resulting cell suspension was plated on flasks coated with $10 \mu \mathrm{g} / \mathrm{mL}$ fibronectin in HUVEC growth media.

\section{Aortic ring, tube formation, and in vivo Matrigel angiogenesis assays}

The aortic ring assays were performed as described previously [18].

The formation of vascular tube-like structures by HUVEC was performed as described previously [40] with modification. We coated 48-well plates with $200 \mu \mathrm{L}$ of growth-factor reduced Matrigel according to the manufacturer's instructions. HUVECs were starved $3 \mathrm{~h}$ in DMEM:F12, $1 \%$ FBS, and $90 \mu \mathrm{g} / \mathrm{mL}$ heparin. The cells were collected by trypsinization, suspended in starvation media, and 60,000 cells were plated per well in the presence or absence of the indicated peptides or VEGF at the indicated concentrations. 16 h later, the cells were washed $2 \times$ in PBS, fixed with $2 \%$ formaldehyde, and bright field images of the wells were taken.

Matrigel angiogenesis assays were done as described [41]. Growth factor-reduced matrigel was mixed with $500 \mathrm{ng} / \mathrm{mL}$ VEGF and $200 \mu \mathrm{M}$ of peptides, and $400 \mu \mathrm{L}$ injected into mice subcutaneously. At seven days, the matrigel implants were surgically removed in OCT freezing medium and $7 \mu \mathrm{m}$ thick sections were prepared. Sections were fixed with $4 \%$ paraformaldehyde, incubated with Rat anti-mouse CD31 (BioLegend), and exposed to anti-rat Alexa Fluor568 (Invitrogen). The slides were mounted with medium (DakoCytomation) and images were taken by a TCS-SP (Leica) microscope. For quantification, the images were analyzed with ImagePro software (Media Cybernetics).

\section{Immunocytochemistry Analysis}

HUVEC were grown in monolayer on glass slides and then treated with fluorescein-labeled peptides for the indicated time periods. The cells were further stained with the lipophilic tracer DiI to stain the cell membrane following the manufacturer's instructions, then fixed with $2 \%$ paraformaldehyde for $10 \mathrm{~min}$, washed, mounted with cover slips, and analyzed by confocal microscopy (Leica).

\section{Tube Formation Analysis}

Network analysis of tube forming HUVEC was performed in an automated fashion using customized visual basic macros developed within Image-Pro Plus (v6.2, Media Cybernetics, Silver Spring, MD). Bright-field images were imported into Image-Pro one-by-one, in batch mode. A high-pass spectral filter was applied to each image to enhance/equalize intensity; enabling application of a fixed threshold to segment the cell network (will be referred to as the "tube mask"). Since branches were sometimes thin (1 pixel thick), node to node branches were often disconnected following segmentation, even though visual observation confirmed continuity. To resolve this issue, a second approach was applied to preserve continuity. A top-hat morphological filter was applied to the original image to enhance the appearance of low intensity signal, and segmented using a fixed intensity and area threshold. This image was then "added" to the tube mask and inverted (intensity across the tube, referred as "lumens of each tube," was converted to 255). Using Euclidean distance map (EDM)-based background clustering, the lumen of each tube was segmented 
such that no lumen was in contact with another. This image was then inverted and "skeletonized" to create continuous single pixelwidth medial lines along the entire tube network. To avoid errors due to the "skeletonization" process, an additional algorithm was applied to cluster nodes that were within a given distance (predetermined value confirmed visually). These nodes were then classified as 3-, 4-, or 5+ branch nodes and summed for each category for output to Microsoft Excel. In addition to incorrect node classification, the skeletonization process can also produce spurious branches. To eliminate these, a "pruning" filter was applied to remove branches of a predefined length connected to a single node. The total number of branches was then summed and exported to Excel. To determine mean node and branch thickness, a Euclidean distance map was generated from the tube mask and "multiplied" by the node and skeletal branch masks respectively. Thickness values were calculated by summing the resulting pixels values in each of these images, multiplying these values by a factor of two and then by the pixel resolution, and lastly dividing by the total number of node pixels or skeletal branch pixels.

\section{Statistical analysis}

Values were expressed as mean plus or minus standard deviations (SD). $\mathrm{P}$ values were based on the paired t-test. All the experiments were repeated at least three or more times. Results were considered statically significant with $\mathrm{P}$ value less than 0.05 .

\section{References}

1. Hynes RO (1987) Integrins: a family of cell surface receptors. Cell 48: 549-554.

2. Hynes RO (2002) Integrins: bidirectional, allosteric signaling machines. Cell 110: 673-687

3. Ma YQ, Oin J, Plow EF (2007) Platelet integrin alpha(IIb)beta(3): activation mechanisms. J Thromb Haemost 5: 1345-1352.

4. Calderwood DA, Zent R, Grant R, Rees DJ, Hynes RO, et al. (1999) The Talin head domain binds to integrin beta subunit cytoplasmic tails and regulates integrin activation. J Biol Chem 274: 28071-28074.

5. Vinogradova O, Velyvis A, Velyviene A, Hu B, Haas T, et al. (2002) A structural mechanism of integrin alpha(IIb)beta(3) "inside-out" activation as regulated by its cytoplasmic face. Cell 110: 587-597.

6. Anthis NJ, Haling JR, Oxley CL, Memo M, Wegener KL, et al. (2009) \{beta\} integrin tyrosine phosphorylation is a conserved mechanism for regulating talininduced integrin activation. J Biol Chem 284: 36700-36710.

7. Cowan KJ, Law DA, Phillips DR (2000) Identification of shc as the primary protein binding to the tyrosine-phosphorylated beta 3 subunit of alpha IIbbeta 3 during outside-in integrin platelet signaling. J Biol Chem 275: 36423-36429.

8. Phillips DR, Nannizzi-Alaimo L, Prasad KS (2001) Beta3 tyrosine phosphorylation in alphaIIbbeta3 (platelet membrane GP IIb-IIIa) outside-in integrin signaling. Thromb Haemost 86: 246-258.

9. Deshmukh L, Gorbatyuk V, Vinogradova O (2010) Integrin beta3 phosphorylation dictates its complex with Shc PTB domain. J Biol Chem 285: 34875-34884.

10. Blystone SD, Williams MP, Slater SE, Brown EJ (1997) Requirement of integrin beta3 tyrosine 747 for beta3 tyrosine phosphorylation and regulation of alphavbeta3 avidity. J Biol Chem 272: 28757-28761.

11. Boettiger D, Huber F, Lynch L, Blystone S (2001) Activation of alpha(v)beta3vitronectin binding is a multistage process in which increases in bond strength are dependent on Y747 and Y759 in the cytoplasmic domain of beta3. Mol Biol Cell 12: 1227-1237.

12. Chandhoke SK, Williams M, Schaefer E, Zorn L, Blystone SD (2004) Beta 3 integrin phosphorylation is essential for Arp3 organization into leukocyte alpha V beta 3-vitronectin adhesion contacts. J Cell Sci 117: 1431-1441.

13. Butler B, Williams MP, Blystone SD (2003) Ligand-dependent activation of integrin alpha vbeta 3. J Biol Chem 278: 5264-5270.

14. Datta A, Huber F, Boettiger D (2002) Phosphorylation of beta3 integrin controls ligand binding strength. J Biol Chem 277: 3943-3949.

15. Byzova TV, Goldman CK, Pampori N, Thomas KA, Bett A, et al. (2000) A mechanism for modulation of cellular responses to VEGF: activation of the integrins. Mol Cell 6: 851-860.

16. Mahabeleshwar GH, Feng W, Reddy K, Plow EF, Byzova TV (2007) Mechanisms of integrin-vascular endothelial growth factor receptor crossactivation in angiogenesis. Circ Res 101: 570-580.

17. Soldi R, Mitola S, Strasly M, Defilippi P, Tarone G, et al. (1999) Role of alphavbeta3 integrin in the activation of vascular endothelial growth factor receptor-2. EMBO J 18: 882-892.

18. Mahabeleshwar GH, Feng W, Phillips DR, Byzova TV (2006) Integrin signaling is critical for pathological angiogenesis. J Exp Med 203: 2495-2507.

\section{Supporting Information}

Figure S1 Sequential connectivity map for VpepB. Figure is produced by GCPN Analysis 2.1.1.

(JPG)

Figure S2 Uptake of $\beta_{3}$ CT derived peptides by EC. Peptides were labeled with fluorescein (green) at the $\mathrm{N}$ termini and added to HUVEG growth media for the indicated times. The plasma membranes were labeled with Dil (red) and nuclei stained with DAPI (blue). The cells were fixed and analyzed by confocal microscopy.

(JPG)

Figure S3 bFGF induced signaling events are not affected by $\mathbf{F 7 4 7}$ or pY747 peptides. HUVEC cells pretreated with peptides as indicated and stimulated with bFGF for $30 \mathrm{~min}$. Total cell lysates were immuno-probed with anti phospho-erk antibodies.

(JPG)

\section{Author Contributions}

Conceived and designed the experiments: OV TVB NM LD GHM. Performed the experiments: NM LD XZW JM GHM MEW BAK. Analyzed the data: XZW NM LD NLM GHM OV TVB. Wrote the paper: ZZW NM LD NLM BAK OV TVB.

19. Napione L, Cascone I, Mitola S, Serini G, Bussolino F (2007) Integrins: a flexible platform for endothelial vascular tyrosine kinase receptors. Autoimmun Rev 7: $18-22$.

20. Serini G, Valdembri D, Bussolino F (2006) Integrins and angiogenesis: a sticky business. Exp Cell Res 312: 651-658.

21. Byzova TV, Kim W, Midura RJ, Plow EF (2000) Activation of integrin alpha(V)beta(3) regulates cell adhesion and migration to bone sialoprotein. Exp Cell Res 254: 299-308

22. Mahabeleshwar GH, Chen J, Feng W, Somanath PR, Razorenova OV, et al. (2008) Integrin affinity modulation in angiogenesis. Cell Cycle 7: 335-347.

23. Vaynberg J, Qin J (2006) Weak protein-protein interactions as probed by NMR spectroscopy. Trends Biotechnol 24: 22-27.

24. Leppanen VM, Prota AE, Jeltsch M, Anisimov A, Kalkkinen N, et al. (2010) Structural determinants of growth factor binding and specificity by VEGF receptor 2. Proc Natl Acad Sci U S A 107: 2425-2430.

25. Harris PA, Cheung M, Hunter RN, 3rd, Brown ML, Veal JM, et al. (2005) Discovery and evaluation of 2-anilino-5-aryloxazoles as a novel class of VEGFR2 kinase inhibitors. J Med Chem 48: 1610-1619.

26. Deshmukh L, Gorbatyuk V, Vinogradova O (2010) Integrin \{beta\}3 phosphorylation dictates its complex with the Shc phosphotyrosine-binding (PTB) domain. The Journal of biological chemistry 285: 34875-34884.

27. Deshmukh L, Meller N, Alder N, Byzova T, Vinogradova O (2011) Tyrosine Phosphorylation as a Conformational Switch: A CASE STUDY OF INTEGRIN beta3 CYTOPLASMIC TAIL. The Journal of biological chemistry 286: 40943-40953.

28. Davis GE, Stratman AN, Sacharidou A, Koh W (2011) Molecular basis for endothelial lumen formation and tubulogenesis during vasculogenesis and angiogenic sprouting. International review of cell and molecular biology 288: 101-165.

29. Law DA, DeGuzman FR, Heiser P, Ministri-Madrid K, Killeen N, et al. (1999) Integrin cytoplasmic tyrosine motif is required for outside-in alphaIIbbeta3 signalling and platelet function. Nature 401: 808-811.

30. Reynolds LE, Wyder L, Lively JC, Taverna D, Robinson SD, et al. (2002) Enhanced pathological angiogenesis in mice lacking beta3 integrin or beta 3 and beta5 integrins. Nature medicine 8: 27-34.

31. Holmqvist K, Cross MJ, Rolny C, Hagerkvist R, Rahimi N, et al. (2004) The adaptor protein shb binds to tyrosine 1175 in vascular endothelial growth factor (VEGF) receptor-2 and regulates VEGF-dependent cellular migration. J Biol Chem 279: 22267-22275.

32. Takahashi T, Yamaguchi S, Chida K, Shibuya M (2001) A single autophosphorylation site on KDR/Flk-1 is essential for VEGF-A-dependent activation of PLC-gamma and DNA synthesis in vascular endothelial cells. EMBO J 20: 2768-2778.

33. Schaffner-Reckinger E, Gouon V, Melchior C, Plancon S, Kieffer N (1998) Distinct involvement of beta3 integrin cytoplasmic domain tyrosine residues 747 and 759 in integrin-mediated cytoskeletal assembly and phosphotyrosine signaling. J Biol Chem 273: 12623-12632. 
34. Czuchra A, Meyer H, Legate KR, Brakebusch C, Fassler R (2006) Genetic analysis of betal integrin "activation motifs" in mice. J Cell Biol 174: 889-899.

35. Vallar L, Melchior G, Plancon S, Drobecq H, Lippens G, et al. (1999) Divalent cations differentially regulate integrin alphaIIb cytoplasmic tail binding to beta3 and to calcium- and integrin-binding protein. J Biol Chem 274: 17257-17266.

36. Delaglio F, Grzesiek S, Vuister GW, Zhu G, Pfeifer J, et al. (1995) NMRPipe: a multidimensional spectral processing system based on UNIX pipes. J Biomol NMR 6: 277-293

37. Vranken WF, Boucher W, Stevens TJ, Fogh RH, Pajon A, et al. (2005) The CCPN data model for NMR Spectroscopy. Proteins 59: 687-696.
38. Wuthrich K (1986) NMR of proteins and nucleic acids. New York: John Wiley \& Sons.

39. Schwieters CD, Kuszewski JJ, Tjandra N, Clore GM (2003) The Xplor-NIH NMR molecular structure determination package. J Magn Reson 160: 65-73.

40. Ward C, Kuehn D, Burden RE, Gormley JA, Jaquin TJ, et al. (2010) Antibody targeting of cathepsin $\mathrm{S}$ inhibits angiogenesis and synergistically enhances antiVEGF. PLoS One 5.

41. Passaniti A (1992) Extracellular matrix-cell interactions: Matrigel and complex cellular pattern formation. Lab Invest 67: 804; author reply 804-808. 